Encapsulation of the therapeutic microbe Akkermansia muciniphila in a double emulsion enhances survival in simulated gastric conditions

van der Ark, Kees C. H.

2017-12

van der Ark, K C H, Nugroho , A D W , Berton-Carabin , C , Wang , C , Belzer , C , de Vos, W M \& Schroen , K 2017 , ' Encapsulation of the therapeutic microbe Akkermansia muciniphila in a double emulsion enhances survival in simulated gastric conditions ' , Food Research International , vol. 102 , pp. 372-379 . https://doi.org/10.1016/j.foodres.2017.09.004

http://hdl.handle.net/10138/298405

https://doi.org/10.1016/j.foodres.2017.09.004

publishedVersion

Downloaded from Helda, University of Helsinki institutional repository.

This is an electronic reprint of the original article.

This reprint may differ from the original in pagination and typographic detail.

Please cite the original version. 


\title{
Encapsulation of the therapeutic microbe Akkermansia muciniphila in a double emulsion enhances survival in simulated gastric conditions
}

\author{
Kees C.H. van der Ark ${ }^{\mathrm{a}}$, Avis Dwi Wahyu Nugroho ${ }^{\mathrm{a}, \mathrm{b}, 1}$, Claire Berton-Carabin ${ }^{\mathrm{b}}$, Che Wang ${ }^{\mathrm{a}, \mathrm{b}, 2}$, \\ Clara Belzer ${ }^{\mathrm{a}}$, Willem M. de Vos ${ }^{\mathrm{a}, \mathrm{c}}$, Karin Schroen ${ }^{\mathrm{b}, *}$ \\ a Laboratory of Microbiology, Wageningen University and Research, Stippeneng 4, Wageningen, The Netherlands \\ ${ }^{b}$ Laboratory of Food Process Engineering, Wageningen University and Research, Bornse Weilanden 9, Wageningen, The Netherlands \\ ${ }^{c}$ RPU Immunobiology, Department of Bacteriology \& Immunology, University of Helsinki, Haartmaninkatu 3, Helsinki, Finland
}

\section{A R T I C L E I N F O}

\section{Keywords:}

Double emulsion

Akkermansia muciniphila

Gut bacteria

Gastric conditions

Therapeutic microbe

\begin{abstract}
A B S T R A C T
There is considerable attention for developing Akkermansia muciniphila as a new therapeutic microbe since it has shown to prevent diet-induced obesity and type 2 diabetes in mice. However, A. muciniphila is sensitive to gastric conditions such as low $\mathrm{pH}$ and oxygen. Therefore, we explored the possibility of encapsulating $A$. muciniphila in a water-in-oil-in-water $(\mathrm{W} / \mathrm{O} / \mathrm{W})$ double emulsion, to allow for protection during gastric passage and subsequent release in the small intestine. The bacteria were efficiently encapsulated in the inner emulsion droplets and remained entrapped during in vitro gastric digestion. The cells were then released in the simulated intestinal phase of the in vitro system. The viability of encapsulated cells was found to be higher when compared to cells dispersed in buffer, that had been subjected to similar mechanical process as the one conducted to prepare the emulsion systems. Surprisingly, the viability of the processed cells was even higher than that of the cells dispersed in buffer without processing, likely due to shear-induced stress tolerance. To conclude, encapsulation in a double emulsion seems to be a promising strategy to protect A. muciniphila during gastric passage in oral formulations.
\end{abstract}

\section{Introduction}

The influence of the gut microbiota on human health has been studied extensively during the past decades. Correlations have been found between microbiota composition and diseases, including but not limited to type 2 diabetes, metabolic syndrome and ulcerative colitis (Clemente, Ursell, Parfrey, \& Knight, 2012; Marchesi et al., 2016). Recently, treatments aiming to change the microbiota composition were employed to fight infections. Faecal transplants by intubation were used to treat chronic infections caused by Clostridium difficile with high effectiveness (van Nood et al., 2013). However, the mode of action of these treatments is poorly understood due to the undefined composition of the faecal matter (van Nood et al., 2013).

In the last year, specific bacterial species from the microbiota have been identified as potential probiotics or even therapeutic microbes (Plovier et al., 2016; Quevrain et al., 2016; Udayappan et al., 2016) that could be used to treat or prevent specific diseases. An important species is the gut bacterium Akkermansia muciniphila, the presence and abundance of which has been reported to inversely correlate with body weight, gut permeability and inflammation (Everard et al., 2013; Wang et al., 2011). This human mucus colonizer was found to be not only important for obesity development and associated metabolic disorders, but also for influencing the host's general health and physiology. Recently, the administration of A. muciniphila by gavage was found to protect mice from diet-induced obesity (Everard et al., 2013; Plovier et al., 2016). Moreover, A. muciniphila was found to be safe for use in humans (Plovier et al., 2016). Incorporating this functional microbe in food products or medicine could be the starting point for obesity and type 2 diabetes prevention; however, the application of $A$. muciniphila may be challenged by its sensitivity to low $\mathrm{pH}$, shear, and oxygen (Derrien, Vaughan, Plugge, \& de Vos, 2004; Ouwerkerk et al., 2016). Besides, survival or growth of A. muciniphila in the presence of bile salts has not been documented yet.

To protect $A$. muciniphila during gastric passage, an effective encapsulation system is needed. Probiotics have commonly been encapsulated in various ways to increase shelf life, viability and targeted

\footnotetext{
* Corresponding author.

E-mail address: karin.schroen@wur.nl (K. Schroen).

${ }^{1}$ Present affiliations: Host-Microbe Interactomics Group, Wageningen University and Research, De Elst 1, Wageningen, The Netherlands; NIZO food research B.V., Kernhemseweg 2, Ede, The Netherlands.

${ }^{2}$ Present affiliation: Food \& Bio-based Products, AgResearch Limited, Palmerston North 4442, New Zealand.
} 
delivery (Anal \& Singh, 2007), although many of these techniques impose high stress on the bacteria. For example, spray drying causes high osmotic pressure, and exposure to oxygen. Additionally, the high temperatures used in spray drying could either reduce bacterial viability and denature proteins that are of importance in probiotic efficacy (Plovier et al., 2016). Extrusion is used for encapsulation in alginate beads, resulting in particles of 2 to $5 \mathrm{~mm}$; the most important limitation of extrusion being susceptibility of the alginate beads to damage (Krasaekoopt, Bhandari, \& Deeth, 2003; Solanki et al., 2013).

In the current study we used W/O/W emulsions for encapsulation ( $\mathrm{Su}$, Flanagan, \& Singh, 2008), which are oil globules, containing small aqueous droplets that are dispersed in an aqueous continuous phase (LealCalderon, Homer, Goh, \& Lundin, 2012). The internal aqueous droplets can serve as an entrapping reservoir for A. muciniphila because of its small size of $\sim 1 \mu \mathrm{m}$. Besides, dedicated emulsification was preferred for $A$. muciniphila because of the rather mild process conditions. Encapsulation of A. muciniphila in the inner droplets of double water-in-oil-in-water $(\mathrm{W} / \mathrm{O} /$ W) emulsions may give protection from adverse external conditions, and also allow targeted delivery in the intestine, as was found for the probiotic Lactobacillus rhamnosus that had a higher relative viability (10-100 fold) after gastric digestions compared to the control (Pimentel-Gonzalez, Campos-Montiel, Lobato-Calleros, Pedroza-Islas, \& Vernon-Carter, 2009; Shima, Morita, Yamashita, \& Adachi, 2006). However, L. rhamnosus has a high acid resistance and can survive an acidity of $\mathrm{pH} 2.5$ (Corcoran, Stanton, Fitzgerald, \& Ross, 2005), whereas A. muciniphila is unable to grow at a pH below 5.5 (Derrien et al., 2004), and needs to be better protected.

The application of $\mathrm{W} / \mathrm{O} / \mathrm{W}$ emulsions is challenging due to the many factors that can contribute to their physical instability. They often consist of large and polydisperse droplets that have a strong tendency for flocculation, creaming and coalescence (Benichou, Aserin, \& Garti, 2004; van der Graaf, Schroen, \& Boom, 2005). In addition, it is difficult to retain the encapsulated matter within the water phase; release may occur as a result of concentration gradients and osmotic pressure difference (Benichou et al., 2004), especially during storage. Bacteriasized particles can even be expelled by coalescence of the inner water phase with the outer water phase. So, localisation of the entrapped bacteria in the $\mathrm{W} / \mathrm{O} / \mathrm{W}$ emulsion during gastric simulation and stabilization of the emulsion itself is imperative. Furthermore, an oil-based emulsion is needed to allow for the release of bacteria after gastric passage, because the oil is degraded by bile upon entering the small intestine.

In this study, we encapsulated A. muciniphila (or fluorescently-labelled particle analogues) in the inner water droplets of double $\mathrm{W} / \mathrm{O} / \mathrm{W}$ emulsions produced via a mild homogenization technique developed in our labs. First, the morphology and physical stability of the emulsions were assessed. Subsequently, we investigated the localisation of bacteria analogues within the emulsions, and finally the survival rate of $A$. muciniphila, when emulsions were subjected to storage and simulated gastrointestinal conditions.

\section{Materials and methods}

\subsection{Media preparation of A. muciniphila}

Liquid culture of A. muciniphila $\mathrm{Muc}^{\mathrm{T}}$ (CIP $107961^{\mathrm{T}}$ ) was prepared in anoxic basal media as described previously (Derrien et al., 2004). The basal media was supplemented with $20 \mathrm{~g} / \mathrm{L}$ tryptone (Oxoid Ltd., $\mathrm{UK}$ ) and $4 \mathrm{~g} / \mathrm{L} \mathrm{L}$-threonine (Sigma-Aldrich, USA). A mixture of $250 \mathrm{mM}$ glucose $(\mathrm{D}(+)$-glucose monohydrate, Merck, Germany) and $N$-acetyl-Dglucosamine (purity $\geq 99 \%$, Sigma-Aldrich, USA) was added by $10 \%$ $\mathrm{v} / \mathrm{v}$ as the carbon source. Media were filled into serum bottles sealed with butyl-rubber stoppers and aluminium crimp caps under anaerobic conditions provided by a gas phase of $182 \mathrm{kPa}(1.5 \mathrm{~atm}) \mathrm{N}_{2} / \mathrm{CO}_{2}$.

For the total viable count (TVC), Brain Heart Infusion (BHI) mucin agar was prepared containing $10 \mathrm{~g}$ agar (bacteriological agar no. 1,
Oxoid Ltd., UK), $37 \mathrm{~g}$ BHI (Becton, Dickinson \& Co, Belgium), $0.5 \mathrm{~g} \mathrm{L-}$ cysteine hydrochloride monohydrate (Sigma-Aldrich, USA), $1 \mathrm{~mL}$ rezasurin, and $5 \mathrm{~g}$ commercial hog gastric mucin (Type III; Sigma, Saint Louis, USA) per litre medium. BHI mucin agar was kept in 2 anaerobic atmosphere generation bags (AnaeroGen ${ }^{\mathrm{TM}}$, Oxoid Ltd., UK) at minimum one day before use and one fresh bag was used during incubation.

\subsubsection{Cultivation and preparation of concentrated glycerol stocks of $A$. muciniphila}

Cultivation of $A$. muciniphila liquid culture was done in anoxic medium by inoculating $1 \% \mathrm{v} / \mathrm{v}$ of 2 days pre-culture. Incubation was done at $37^{\circ} \mathrm{C}$ for $2-3$ days until late exponential phase. Cells were harvested by centrifugation at $10,000 \mathrm{~g}$ for $10 \mathrm{~min}$ and washed twice in buffer A (Phosphate Buffered Saline (PBS), $10 \mathrm{mM} \mathrm{pH} 7.4$ with additional $\mathrm{NaCl}: 0.2 \mathrm{~g} / \mathrm{L} \mathrm{KCl}, 0.23 \mathrm{~g} / \mathrm{L} \mathrm{KH}_{2} \mathrm{PO}_{4}, 2 \mathrm{~g} / \mathrm{L} \mathrm{NaCl}, 1.15 \mathrm{~g} / \mathrm{L}$ $\left.\mathrm{Na}_{2} \mathrm{HPO}_{4}\right)$. The harvested cells were then added by $1: 1(\mathrm{v} / \mathrm{v})$ ratio to anaerobic vials containing $50 \% \mathrm{v} / \mathrm{v}$ glycerol in water. Cells were preserved at $-80{ }^{\circ} \mathrm{C}$ until use. One vial was thawed and counted by TVC as the reference concentration for all other experiments. For the use at non-microbiological laboratory, the cells were pasteurized at $68^{\circ} \mathrm{C}$ in a water bath for $30 \mathrm{~min}$ prior to use, to render them inactive.

\subsubsection{Preparation and characterisation of double emulsions}

Before use, both rotor-stator homogenizer and premix emulsification system were cleaned and filled with $1 \%$ halamid (Chloramine-T, Boom B.V., The Netherlands) solution for $10 \mathrm{~min}$. The system was emptied and refilled with sterile water to wash the remaining halamid. Water-in-oil $\left(\mathrm{W}_{1} / \mathrm{O}\right)$ emulsion (3:7, v/v) was firstly prepared by combining a freshly prepared solution of $10^{9} \mathrm{CFU} / \mathrm{mL}$ A. muciniphila in PBS $10 \mathrm{mM}+2 \mathrm{~g} / \mathrm{L} \mathrm{NaCl}$ with $1 \% \mathrm{w} / \mathrm{v}$ PGPR (Givaudan, Switzerland) in sunflower oil (C1000, The Netherlands) in $50 \mathrm{~mL}$ conical centrifuge tube. The glycerol stocks used throughout the project were thawed only once and were not refrozen. The water and oil mixture was homogenized with a rotor-stator homogenizer (Ultraturrax T-18, IKA, Germany) at 4400 RPM for 6 min with manual up-and-down moving every minute to ensure uniform homogenization.

Afterward, the resulting primary emulsion was added to the outer water phase containing $1 \% \mathrm{w} / \mathrm{v}$ sodium caseinate (sodium caseinate $\mathrm{S}$ $80 \%$ purity, DMV international, The Netherlands) in PBS $10 \mathrm{mM}+2 \mathrm{~g}$ / $\mathrm{L} \mathrm{NaCl}$ that had been stirred overnight. The volume fraction of $\mathrm{W}_{1} / \mathrm{O}$ emulsion was $10 \%$ of the total double emulsion volume. A coarse double emulsion was first made with the rotor-stator homogenizer at 3400 RPM for 6 min, prior to emulsification with a premix column at 4 bar (pressurized $\mathrm{CO}_{2}$ ) for 5 passes. The procedure was similar to that used in previous work (Sahin, Sawalha, \& Schroën, 2014), except that it was carried out without nickel sieve and glass beads. The obtained double emulsion was kept in a $1 \mathrm{~L}$ bottle sealed with butyl-rubber stoppers and aluminium screw cap under anaerobic condition. A total volume of $300 \mathrm{~mL}$ double emulsions was made per batch.

All preparations were done in triplicate; the primary and double emulsions were characterized for droplet morphology and droplet size distribution. Droplet morphology was observed using bright field confocal microscope at $400 \times$ magnification. A volume of $4 \mu \mathrm{L}$ sample was used for all microscopy preparations throughout the project unless stated otherwise. For each sample, the droplet size distribution was measured in triplicate using a light scattering instrument (Mastersizer 2000, Malvern, UK) with the values indicated in Table A1 (Appendix A, Supplementary materials and methods). The window glass pair was cleaned with soap and ethanol air every 3 to 4 measurements to ensure accurate detection.

In case of measurement of double emulsions containing living bacteria, measurement was done using 15 microscopy images processed by automated image analysis software (ImageJ 1.49o) and MS. Excel 2010 (Appendix A, Supplementary materials and methods). All values of droplet size were expressed as volume-weighted mean diameter (D $[4,3]$ ). The following formula (Eq. (1)) was used for the calculation of D 
$[4,3]$ in MS. Excel:

$\mathrm{D}(4,3)=\frac{\sum n_{i} d_{i}^{4}}{\sum n_{i} d_{i}^{3}}$

where $n_{i}$ is expressed as the number of particles in each size-class per unit volume of emulsion, while $d_{i}$ is the diameter of the particles in each size-class. The width of the distribution (Span) was determined as follows (Eq. (2)):

Span $=\frac{d(0.9)-d(0.1)}{d(0.5)}$

where $d(0.1), d(0.5)$ and $d(0.9)$ are the sizes below which $10 \%, 50 \%$ and $90 \%$ of the particles are counted, respectively.

Alternatively, the program ImageJ was used to analyse 15 microscopy images. First, the image was converted to black and white, after which the threshold was adjusted to show the desired droplets. Additionally, outliers were removed to exclude small primary emulsion droplets. Finally, the particles with a radius of $10 \mu \mathrm{m}$ to infinity and a circularity of $0.50-1.00$ were analysed. The output was used to calculate the D [4, 3] according to Eq. (1).

The osmotic pressure on the droplets exerted by the outer water phase was calculated by using the Van't Hoff equation:

$\Pi=n \times C \times R \times T$

In which $\Pi$ is the osmotic pressure, $T$ in Kelvin, $R$ the gas constant, $C$ the concentration of the compounds, and $n$ the amount of dissociated compounds.

\subsubsection{Bacterial viability and emulsion stability during storage}

A freshly prepared double emulsion loaded with bacteria was stored in anaerobic serum bottles with a $\mathrm{N}_{2} / \mathrm{CO}_{2}$ headspace and in aerobic conical centrifugation tubes. The same was done with an equal amount of bacteria in $10 \mathrm{mM}$ PBS buffer as a control. Each bottle contained $10 \mathrm{~mL}$ of liquid. After these treatments, the samples were kept in the fridge at $4{ }^{\circ} \mathrm{C}$ and samples were taken at $0,2,24,48$ and $72 \mathrm{~h}$. At each time point, $0.5 \mathrm{~mL}$ sample of the experimental group and the control group were taken under sterile conditions. To count the viable cells, the double emulsions underwent centrifugation steps $(10,000 \mathrm{~g}$ for $10 \mathrm{~min})$ to break down the emulsion and fully separate the oil layer and water layer (water phases 1 and 2). The complete sample was mixed with a vortex agitator for $10 \mathrm{~s}$ to suspend the bacteria. Serial dilutions $\left(10^{-1}\right.$ to $10^{-7}$ ) were made of each sample in PBS. Spots of $2 \mu \mathrm{L}$ were made from each dilution on BHI-mucin-agar plates, prepared as described above. The plates were incubated for two days at $37^{\circ} \mathrm{C}$.

The droplet size distribution, morphology, and encapsulation efficiency were set as standards to evaluate the physical properties of the double emulsion systems. The double emulsions were stored at $4{ }^{\circ} \mathrm{C}$ for $96 \mathrm{~h}$ for the stability tests, and samples were taken at 0, 1, 2, 4, 24, 48, and $96 \mathrm{~h}$. The whole set of experiments was conducted twice and each experiment contained two parallel cultures for each condition.

\subsubsection{Localisation and encapsulation efficiency of bacteria and fluorescent particles}

Double emulsions were prepared with hydrophilic fluorescent particles (FluoSpheres ${ }^{\circledast} 1 \mu \mathrm{m}$ F-13081, maximum emission wavelength $505 \mathrm{~nm}$, ThermoFisher Scientific, USA) or pasteurized biomass which was labelled by $0.3 \% \mathrm{v} / \mathrm{v}$ of $3.34 \mathrm{mM}$ SYTO $\left(\lambda_{\text {em }} 608 \mathrm{~nm}\right.$, ThermoFisher Scientific, USA). The double emulsions were subjected to simulated digestion (see detailed procedure below in Section 2.3) and samples were observed under fluorescence microscope. Green light $(\lambda=540 \mathrm{~nm})$ was used for the excitation.

The encapsulation efficiency was calculated based on the average of 30 random microscopic images $(400 \times$ magnification) from samples stored for different time periods.

The encapsulation efficiency was calculated as follows (Eq. (4)):
Encapsulation efficiency $(\%)=\frac{1}{30} \sum_{i=1}^{30} a_{i}=\frac{1}{30}\left(a_{1}+a_{2}+\cdots+a_{n}\right)$

where

$\mathrm{a}_{i}=\frac{\text { number of fluorescent particles entrapped in inner water droplets }}{\text { total number of fluorescent particles in view }}$

\subsection{Simulated digestion test}

The international consensus of standardized static in vitro digestion method by Minekus et al. (Minekus et al., 2014) was applied with some modifications (Table A2, Appendix A, Supplementary materials and methods). The tests were done in chemostat bioreactors (DASGIP ${ }^{\circledR}$ Parallel Bioreactor System, Eppendorf, Germany), each with a total volume of $500 \mathrm{~mL}$. The gastric test was done at $\mathrm{pH} 3.0,37{ }^{\circ} \mathrm{C}, 2 \mathrm{~h}$, and $100 \mathrm{RPM}$ agitation with $0.2 \% \mathrm{w} / \mathrm{v}$ pepsin (from porcine gastric mucosa 3200-4500 $\mathrm{U} \mathrm{mg}^{-1}$ protein, Sigma, USA), diluted in simulated gastric fluid (SGF) pH 6.0 (Table A3, Appendix A, Supplementary materials and methods). The intestinal test was done at $\mathrm{pH} 7.0,37^{\circ} \mathrm{C}, 2 \mathrm{~h}$, and $100 \mathrm{RPM}$ agitation with $0.48 \% \mathrm{w} / \mathrm{v}$ porcine bile extract (B8631, SigmaAldrich, USA) and $0.22 \% \mathrm{w} / \mathrm{v}$ pancreatin (from porcine pancreas, $8 \times$ USP specification, Sigma-Aldrich, USA).

Potassium hydroxide (3 M) and sulfuric acid (0.5 M) were used to control the $\mathrm{pH}$ during the experiment. Dissolved oxygen was programmed for gradual decrease during $2 \mathrm{~h}$ gastric test until anaerobic conditions were reached and maintained during the intestinal phase. Pure nitrogen was used to alter the atmospheric composition in the vessels. Samples were taken before and after each digestion stage, kept on ice and observed by phase contrast confocal microscopy at $400 \times$. Each microscope slide was prepared just before observation to keep droplets intact. For viable cell counts, the double emulsions were disrupted by centrifugation at $10,000 \mathrm{~g}$ for $10 \mathrm{~min}$ prior to TVC plating on BHI mucin.

All equipment and materials were sterilized except the enzyme solutions. Additional antibiotics were added with final concentration of $5 \mu \mathrm{g} / \mathrm{mL}$ vancomycin hydrochloride ( $>900 \mu \mathrm{g} / \mathrm{mg}$, AcrosOrganics, Belgium) and $50 \mu \mathrm{g} / \mathrm{mL}$ kanamycin sulfate (Sigma-Aldrich, USA) during the digestion test and in BHI-mucin-agar to avoid contamination and growth of undesired cells. Both processed and unprocessed cells dispersed in PBS were tested as control. In the former case, a bacterial suspension in PBS buffer was subjected to the same mechanical treatment as applied for preparing the double emulsions, i.e., 2 treatments with the rotor-stator homogenizer, followed by the premix column emulsification step.

\subsection{Further analysis and blanks}

2.3.1. Zeta potential of sodium-caseinate-stabilized droplets at different $p H$

In order to assess the effect of $\mathrm{pH}$ changes on the behavior of oil droplets coated with sodium caseinate, additional (simple $\mathrm{O} / \mathrm{W}$ ) emulsions were prepared by mixing sunflower oil (10\% volume fraction) with $1 \%$ sodium caseinate in PBS $+2 \mathrm{~g} / \mathrm{L} \mathrm{NaCl}$, which was set at different $\mathrm{pH}$ values (1, 3, 5, 7, and 9). The mixture was homogenized at $6000 \mathrm{RPM}$ for $10 \mathrm{~min}$. The charge of the resulting emulsion droplets was analysed using Malvern Zetasizer Nano S (Malvern, UK). Prior to analysis, samples were diluted 10 times with deionized water. The measurement was done 3 times for each sample with an equilibration time of $300 \mathrm{~s}$.

\subsubsection{Utilization and resistance of bile extract}

Pre-culture of $A$. muciniphila was added at $1 \% \mathrm{v} / \mathrm{v}$ to anoxic tryptone media containing different concentration of porcine bile extract $(0.05 \%, 0.1 \%, 0.5 \%$ and $1 \%$, Bile extract porcine, Sigma-Aldrich, USA). All media were supplemented with $10 \% \mathrm{v} / \mathrm{v}$ of a $125 \mathrm{mM} n$ - 
acetylglucosamine and $125 \mathrm{mM}$ glucose solution. Each treatment was done in duplicate. The culture was incubated at $37^{\circ} \mathrm{C}$ and optical density at $600 \mathrm{~nm}$ was measured. Anoxic tryptone medium with sugars was used as the positive control.

\subsubsection{Statistical analyses}

The cell survival during digestion tests for both treatments (i.e., encapsulated bacteria and control) was analysed using two-way ANOVA on SPSS Statistics (version 23, IBM). One-way ANOVA was used to compare the protection in the gastric test. A Student's $t$-test in Microsoft Excel 2010 was used to compare the methods to measure droplets size. The analysis of cell release was also done using a paired $t$ test. Significant differences were considered at the level of $p \leq 0.05$. Standard errors of means were obtained and are shown as error bars in figures and tables.

\section{Results and discussion}

\subsection{Droplet size characterisation}

An important prerequisite for developing the double emulsion delivery system was that the inner water droplets should be large enough to allow encapsulation of $A$. muciniphila cells, which have a size of 0.6-1.0 $\mu \mathrm{m}$ (Derrien et al., 2004). Therefore, the preparation conditions for the primary $(\mathrm{W} / \mathrm{O})$ emulsions were chosen such that water droplets $\left(\mathrm{W}_{1}\right)$ of around $3.5 \mu \mathrm{m}$ (Table 1 and Fig. 1) were obtained, which is suitable to accommodate single or paired cells of $A$. muciniphila.

The fraction of primary emulsion in the total emulsion was chosen such that a high load of bacteria per gram of emulsion was obtained as presented in Table A4. Quite remarkably, the oil droplet diameter increased in $24 \mathrm{~h}$ from $15 \mu \mathrm{m}$ to a stable value of around $24-25 \mu \mathrm{m}$ (Table 1). The diameter increased by a 1.6 factor, which is equivalent to a 4.6 swelling factor (defined as the ratio of droplet volume at time $t$ to droplet volume at $t=0$ ). This swelling was consistently observed in various trials of the present study (See Appendix A, Supplementary results, Fig. A1 and Fig. A2). The shift of the distribution of droplet size diameter can be seen in Fig. 1. All distributions were overall monomodal and normal.

Both coalescence of oil droplets or water diffusion from outer to inner water phase (swelling) would result in larger droplet diameters. Such a diffusion process was previously shown to occur in comparable double emulsions (Eisinaite, Juraite, Schroen, \& Leskauskaite, 2016). Although swelling has been shown to be one of the main challenges for the application of double emulsions, it can sometimes be used on purpose to, e.g., increase the emulsion's viscosity post-preparation (Bahtz et al., 2015; Leal-Calderon et al., 2012). According to Yan and Pal (2001), water transfer from the external to the internal water phase is mainly caused by osmotic pressure differences that cause rapid swelling. In the present work, the inner and outer water phases were formulated from the same PBS buffer (A); the only differences being sodium caseinate $(1 \% \mathrm{w} / \mathrm{v})$ added to the outer water phase, while the inner water phase contained glycerol stock of bacteria. Based on the following assumptions: final concentration of glycerol in $\mathrm{W}_{1}$ phase approximately $85.5 \mathrm{mM}$, sodium related to caseinate was $1.3 \%$, and

Table 1

Average volume weighted mean diameter $(\mathrm{D}[4,3])$ of inner water droplets $\left(\mathrm{W}_{1}\right)$ and oil droplets (O) over 4-day storage at $4{ }^{\circ} \mathrm{C}$.

\begin{tabular}{|c|c|c|c|c|c|}
\hline Droplets & $\mathrm{W}_{1}$ & $\mathrm{O}$ & & & \\
\hline Time (h) & 0 & 0 & 24 & 48 & 96 \\
\hline $\begin{array}{c}\text { Average D } \\
\qquad[4,3] \\
(\mu \mathrm{m})\end{array}$ & $3.5 \pm 0.3$ & 15.10 .6 & $24.0 \pm 0.9$ & $24.7 \pm 1.3$ & $25.1 \pm 1.5$ \\
\hline Span & $1.3 \pm 0.1$ & $1.5 \pm 0.0$ & $1.7 \pm 0.1$ & $1.6 \pm 0.0$ & $1.6 \pm 0.1$ \\
\hline
\end{tabular}

bacterial cells having the same osmotic pressure as the used buffer, the total osmotic pressure difference was calculated to be $1.96 \times 10^{2} \mathrm{~Pa}$. Following Leal-Calderon et al., 2012, we calculated an induced swelling of a factor or 1.2, while we experimentally determined 4.6 from the oil droplet size. This indicates that also coalescence occurred, and that both effects contributed to the observed increase in droplet size over $24 \mathrm{~h}$.

\subsection{Encapsulation efficiency and viability}

\subsubsection{Encapsulation efficiency of double emulsions}

The encapsulation efficiency of bacteria was emulated by the use of $1 \mu \mathrm{m}$ fluorescent particles and calculated with Eq. (4). We found a high initial particle encapsulation efficiency of $97.5 \%$, which decreased to $89.6 \%$ after 4 days. As such relatively large hydrophilic particles are unlikely to migrate through the oil phase, the observed decrease was most probably caused by release of inner droplets $\left(\mathrm{W}_{1}\right)$ into the outer water phase $\left(\mathrm{W}_{2}\right)$, but please note that encapsulation efficiency remained high, and particle release was minimal. When using non-labelled cells, it was found that colonies on BHI-mucus plates were only observed after breaking the emulsion with centrifugation. If the emulsion was not broken, no colonies were observed. This indicates that all viable cells were encapsulated.

\subsubsection{Viability during storage}

Double emulsions loaded with cells were stored for 3 days in both anaerobic and aerobic conditions. For both conditions, a control was included, consisting of cells simply dispersed in PBS. After one day, only cells stored anaerobically and dispersed in PBS showed no decrease in viability. After two days, the viability decreased in all conditions, but the viability in the PBS buffer remained high under anaerobic conditions (Fig. 2). For the conditions used, no statistical differences were found between any of the end points $(\mathrm{p}>0.12)$.

\subsection{Digestive tests}

\subsubsection{Emulsion morphology during in vitro gastric digestion}

Droplet morphology changes in each stage of the simulated digestion, shown in Fig. 3. In this series of experiments, the double emulsions had an initial diameter of $17.7 \pm 0.3 \mu \mathrm{m}$. The microscopic appearance of the double emulsions just after preparation is shown in Fig. 3a. When brought into contact with pepsin and electrolytes, the droplets flocculated, which can be seen in Fig. 3b. To be complete, immediately after sample addition the $\mathrm{pH}$ of the simulated gastric fluid (SGF) increased from $\mathrm{pH} 3.0$ to $\mathrm{pH} 4.9-5.5$, before the system went back to a $\mathrm{pH}$ value of 3.0, and this can explain the immediate occurrence of droplet flocculation (as also further explained in Appendix A, Section A2.3, Fig. A3). Briefly, at pH 5 the zeta potential is low, and electrostatic repulsion between droplets is minimal. Besides, the presence of calcium and other metal ions in the gastric fluid may enhance droplet flocculation through electrostatic screening (Dickinson, 2010; Hunt \& Dalgleish, 1996; Parker \& Dalgleish, 1981), and calcium bridges may form at low $\mathrm{pH}$ with the phosphoseryl residues of $\alpha$-casein and $\beta$-casein. Furthermore, porcine pepsin will hydrolyse caseinate leading to destabilization and coalescence of the double emulsions, since the smaller peptides have a different affinity for the interface (Nik, Wright, \& Corredig, 2010). After $2 \mathrm{~h}$ exposure to gastric fluid, large oil droplets were present with various morphology, with inner water droplets still present (Figs. 3c, 4b).

At the end of the gastric test, the digestion was shifted to intestinal conditions, and emulsion droplets having a diameter of $10 \mu \mathrm{m}$ could barely be seen after $2 \mathrm{~h}$ (Fig. 3d); the few remaining oil droplets seemed nearly depleted from inner droplets. This shows that the fate of the emulsion is mainly determined in the intestinal phase, where the oil is digested. The disappearance of oil droplets was expected, since 70-90\% of the fat is hydrolysed in the small intestine of the human body 


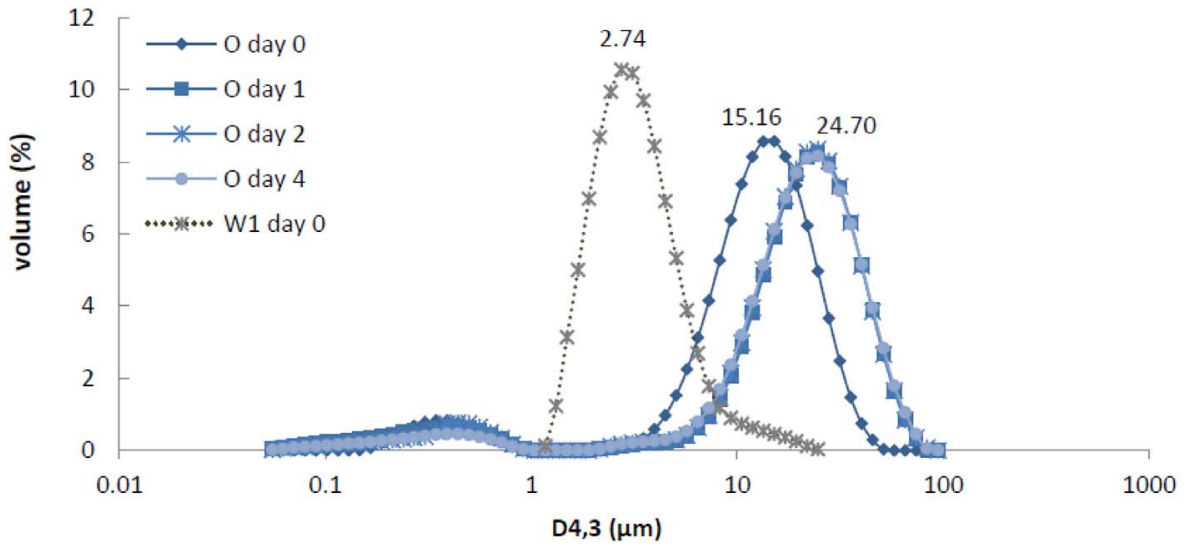

Fig. 1. Droplet size distribution of the water and oil droplets. Droplet size distribution of inner water droplets $\left(W_{1}\right)$ in the primary $\mathrm{W} / \mathrm{O}$ emulsion, and of oil droplets $(\mathrm{O})$ in the double emulsion over 4 day storage at $4{ }^{\circ} \mathrm{C}$.
(Maldonado-Valderrama et al., 2008). Bile salts aid lipolysis by competitively displacing protein emulsifier (Vinarov et al., 2012), and thus allowing lipase and colipase to adsorb on the lipid surface and carry out lipolysis (Maldonado-Valderrama, Wilde, Macierzanka, \& Mackie, 2011), irrespective of droplet size (Begley, Gahan, \& Hill, 2005).

3.3.2. Localisation of entrapped particles and A. muciniphila cells during gastric passage

To investigate localisation within the double emulsion when subjected to digestive conditions, a test was done using fluorescently-labelled bacteria (Fig. 4). Right after preparation, cells were observed in the inner water phase (Fig. 4a), and during the gastric phase (see Fig. 4b), the cells remained there even though the oil globules were coalescing. In this phase, contact of bacterial cells and gastric fluid was minimized, which is very important to create a protective effect (see encapsulation Section 3.3.3). The oil droplets that appear as opaque spheres during the intestinal phase (Fig. 4c), did not contain labelled bacteria but the continuous phase of the digested emulsion did. Additionally, no inner water droplets were observed at this stage and only few oil droplets.

The release of cells was confirmed by total viable cell counting of samples obtained after the intestinal phase (with and without breaking the emulsion), and the total numbers of bacteria were shown to be similar ( $p>0.05$; Fig. 5). This also indicates that most cells were released at the end of the intestinal phase, given their sensitivity to the digestive conditions used.
3.3.3. Increased viability of encapsulated A. muciniphila during gastric passage

A. muciniphila survival was tested throughout simulated digestion using double emulsions and appropriate controls (freely dispersed cells in PBS buffer that have received the same processing as the double emulsion or are only dispersed (Fig. 6). The relative viability of the nonencapsulated bacteria in the gastric juice $(2 \mathrm{~h})$ decreased by $>100$ fold, and only $0.4 \%$ of the control bacteria survived. The non-processed bacteria showed an even higher loss of viability in the gastric phase since only $0.02 \%$ survived. On the other hand, the bacteria encapsulated in the double emulsion were more resistant to the gastric phase, leading to an equivalent survival of $6.6 \%$. All differences are significant ( $\mathrm{p}<0.05)$, also after the intestinal phase during which the viability increased for both controls in PBS, but further decreased for the encapsulated bacteria. This could be due to the delayed exposure to bile that may stimulate the growth of $A$. muciniphila (see Fig. A4).

Other researchers have reported the use of double emulsion microencapsulation for probiotic species. Similar results were observed with Lactobacillus acidophilus (Shima et al., 2006) in which encapsulation at inner phase volume ratios between 0.03 and 0.45 resulted in 10-100 times higher survival after $2 \mathrm{~h}$ gastric testing. Double emulsion encapsulation of $L$. rhamnosus (Pimentel-Gonzalez et al., 2009) also exhibited approximately 100 times higher survival difference compared to control. However, this higher survivability cannot be directly compared to those of $A$. muciniphila, mainly due to different sensitivity to dissolved oxygen (Jyoti, Suresh, \& Venkatesh, 2004; Talwalkar \& Kailasapathy, 2004), (Ouwerkerk et al., 2016). It is known

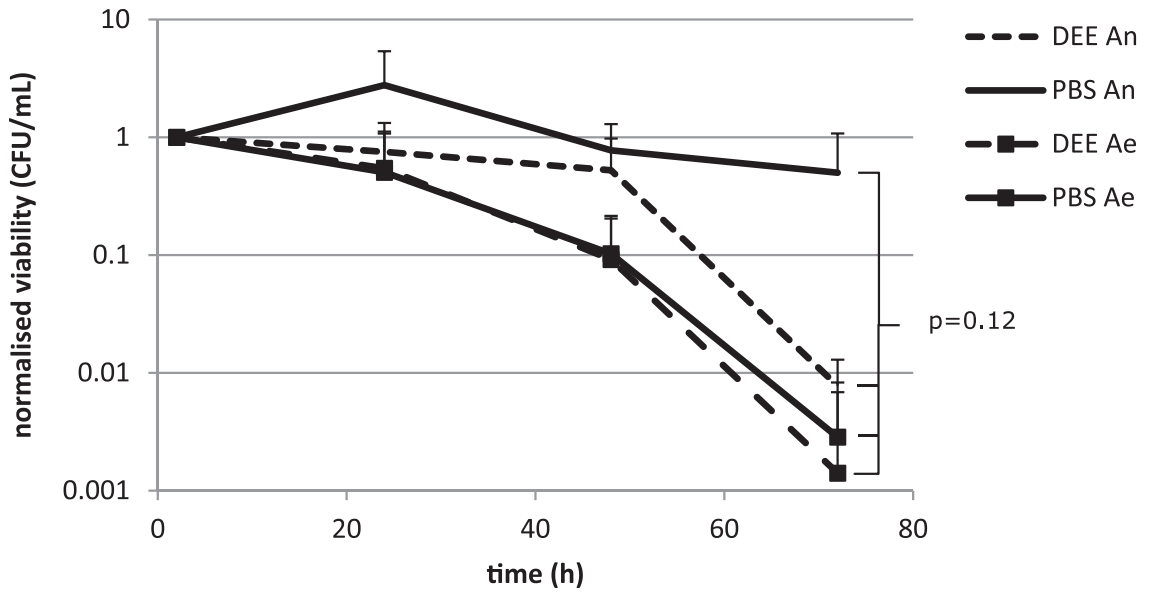

Fig. 2. Viability of encapsulated $A$. muciniphila during storage. The viability of $A$. muciniphila during storage at $4{ }^{\circ} \mathrm{C}$ while encapsulated in a double emulsion or freely dispersed in PBS (DEE $=$ Double Emulsion Encapsulated, PBS $=$ free dispersed in PBS, $\mathrm{An}=$ anaerobic, Ae = aerobic). The data were normalised to the viability after $2 \mathrm{~h}$. Only the bacteria stored anaerobically in PBS show no decrease in viability over $72 \mathrm{~h}$, but the differences were not significant, $\mathrm{p}=0.12$. 


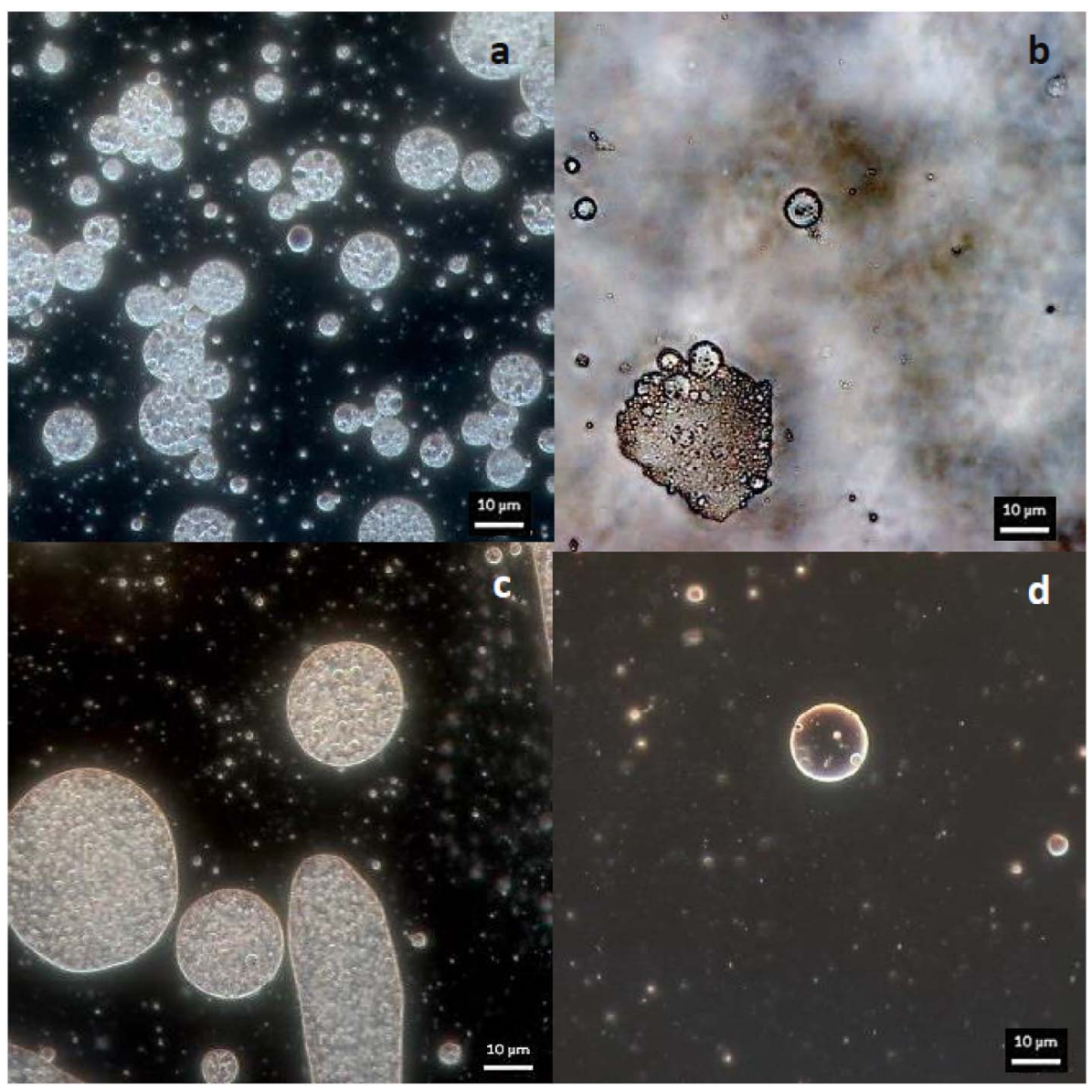

Fig. 3. Double emulsion droplet morphology in stages of the simulated gastrointestinal digestion. The samples were observed at $400 \times$ magnification using phase contrast microscopy (a) before digestion (b) flocculation after immediate contact with gastric fluid, (c) after $2 \mathrm{~h}$ gastric conditions (d) after $2 \mathrm{~h}$ intestinal condition. Scale bar is $10 \mu \mathrm{m}$.

that oxygen, other gases and small non-electrolyte solutes can diffuse through oil and membranes (Walter \& Gutknecht, 1986), and the resulting stress may have induced tolerance in the cells which could explain the difference between processed and non-processed cells dispersed in PBS (Abee, Wels, de Been, \& den Besten, 2011; den Besten et al., 2010).

\section{Conclusion}

We have shown that the viability of $A$. muciniphila after passage through an in vitro gastric system is enhanced by its encapsulation in a double emulsion. Upon addition of the emulsion to gastric conditions, the oil droplets flocculate, but the bacteria remain entrapped inside the inner water phase. Upon the introduction of intestinal liquid, the emulsion is digested and the bacteria are released. Hence, double emulsions seems to be promising systems for encapsulation and targeted intestinal delivery of health-promoting bacteria.

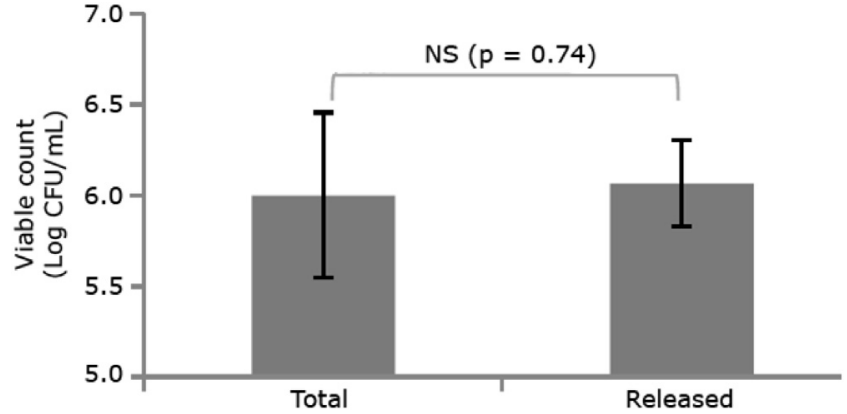

Fig. 5. The viability of released A. muciniphila after in vitro digestion. The total amount of cells was obtained by breaking the emulsion, the released fraction by directly plating the digestate. There is no observed difference $(\mathrm{p}=0.74)$ between the total amount and released bacteria.

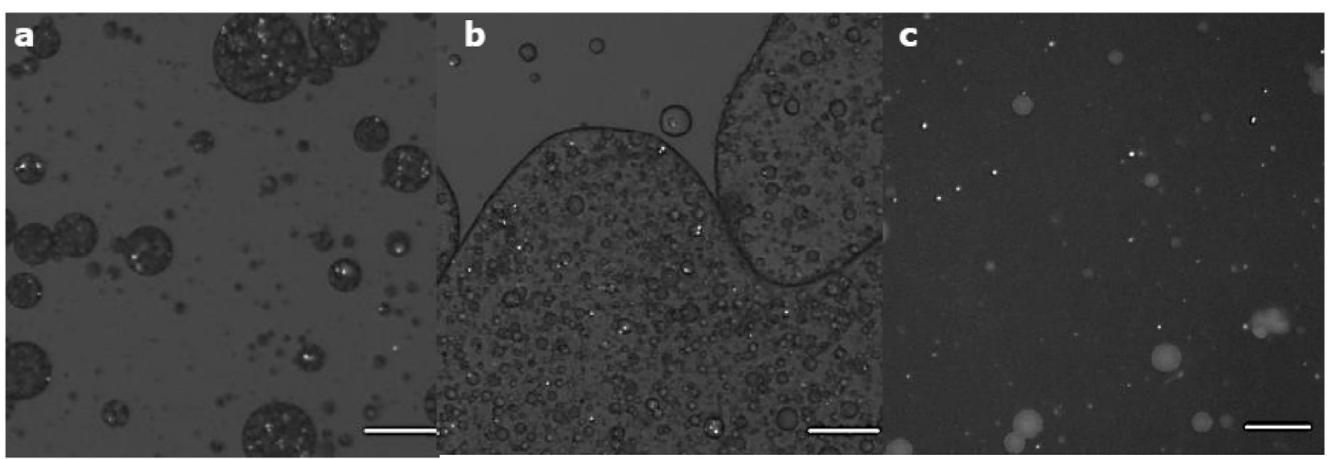

Fig. 4. Double emulsions with fluorescencelabelled cells during each stage of simulated digestion. (a) Before digestion (b) after gastric phase (c) after intestinal phase. The scale bar represents $20 \mu \mathrm{m}$. Cells were observed as white dots. Oil globules that don't contain cells show up as opaque spheres. 


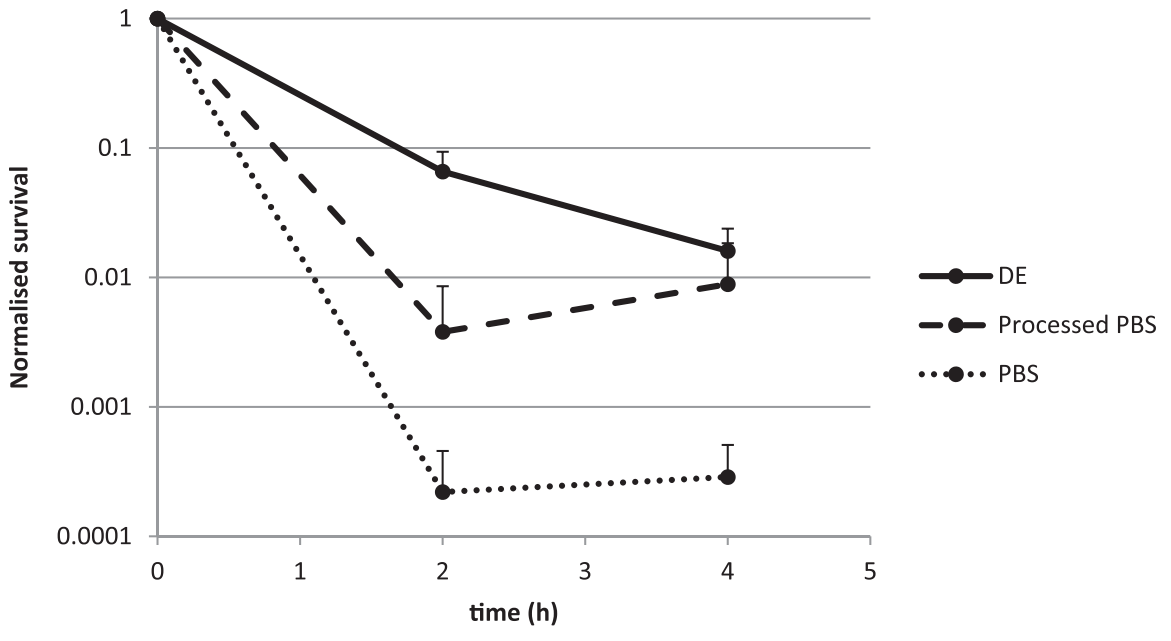

Fig. 6. Survival of $A$. muciniphila after gastric and intestinal passage. The normalised survival of $A$. muciniphila after $2 \mathrm{~h}$ incubation in gastric juice and subsequent $2 \mathrm{~h}$ incubation in intestinal fluid. Bacteria encapsulated in a double emulsion (DE, full line) had a higher survival than bacteria that were mechanically processed in PBS (dashed line). The lowest survival was obtained for bacteria that were only dispersed in PBS (dotted line). Error bars indicate standard deviation, only positive values are indicated.

\section{Conflicts of interest}

None.

\section{Contributors}

KCHvdA, ADWN and CW designed and performed experiments, analysed and interpreted results, generated figures and tables. KCHvdA, CB-C and ADWN conceived the manuscript. WMdV and KS initiated and supervised the project and contributed to the writing of the manuscript. $\mathrm{CB}-\mathrm{C}$ and $\mathrm{CB}$ supervised experimental work and daily progress and contributed to the writing of the manuscript.

\section{Funding}

The work was supported by the Netherlands Organization for Scientific Research (Spinoza Award and SIAM Gravity Grant 024.002.002) granted to WMdV.

The funding organizations had no role in design of the study and collection, analysis, and interpretation of data and in writing the manuscript.

\section{Appendix A. Supplementary data}

Supplementary data to this article can be found online at http://dx. doi.org/10.1016/j.foodres.2017.09.004.

\section{References}

Abee, T., Wels, M., de Been, M., \& den Besten, H. (2011). From transcriptional landscapes to the identification of biomarkers for robustness. Microbial Cell Factories, 10.

Anal, A. K., \& Singh, H. (2007). Recent advances in microencapsulation of probiotics for industrial applications and targeted delivery. Trends in Food Science \& Technology, 18(5), 240-251.

Bahtz, J., Gunes, D. Z., Hughes, E., Pokorny, L., Riesch, F., Syrbe, A., ... Windhab, E. J. (2015). Decoupling of mass transport mechanisms in the stagewise swelling of multiple emulsions. Langmuir, 31(19), 5265-5273.

Begley, M., Gahan, C. G. M., \& Hill, C. (2005). The interaction between bacteria and bile. FEMS Microbiology Reviews, 29(4), 625-651.

Benichou, A., Aserin, A., \& Garti, N. (2004). Double emulsions stabilized with hybrids of natural polymers for entrapment and slow release of active matters. Advances in Colloid and Interface Science, 108-109, 29-41.

den Besten, H. M. W., Arvind, A., Gaballo, H. M. S., Moezelaar, R., Zwietering, M. H., \& Abee, T. (2010). Short- and long-term biomarkers for bacterial robustness: A framework for quantifying correlations between cellular indicators and adaptive behavior. PloS One, 5(10).

Clemente, J. C., Ursell, L. K., Parfrey, L. W., \& Knight, R. (2012). The impact of the gut microbiota on human health: An integrative view. Cell, 148(6), 1258-1270.

Corcoran, B. M., Stanton, C., Fitzgerald, G. F., \& Ross, R. P. (2005). Survival of probiotic Lactobacilli in acidic environments is enhanced in the presence of metabolizable sugars. Applied and Environmental Microbiology, 71(6), 3060-3067.

Derrien, M., Vaughan, E. E., Plugge, C. M., \& de Vos, W. M. (2004). Akkermansia

muciniphila gen. nov., sp nov., a human intestinal mucin-degrading bacterium. International Journal of Systematic and Evolutionary Microbiology, 54, 1469-1476.

Dickinson, E. (2010). Flocculation of protein-stabilized oil-in-water emulsions. Colloids and Surfaces. B, Biointerfaces, 81(1), 130-140.

Eisinaite, V., Juraite, D., Schroen, K., \& Leskauskaite, D. (2016). Preparation of stable food-grade double emulsions with a hybrid premix membrane emulsification system. Food Chemistry, 206, 59-66.

Everard, A., Belzer, C., Geurts, L., Ouwerkerk, J. P., Druart, C., Bindels, L. B., ... Cani, P. D. (2013). Cross-talk between Akkermansia muciniphila and intestinal epithelium controls diet-induced obesity. Proceedings of the National Academy of Sciences of the United States of America, 110(22), 9066-9071.

van der Graaf, S., Schroen, C. G. P. H., \& Boom, R. M. (2005). Preparation of double emulsions by membrane emulsification - A review. Journal of Membrane Science, 251(1-2), 7-15.

Hunt, J. A., \& Dalgleish, D. G. (1996). The effect of the presence of $\mathrm{KCl}$ on the adsorption behaviour of whey protein and caseinate in oil-in-water emulsions. Food Hydrocolloids, 10(2), 159-165.

Jyoti, B. D., Suresh, A., \& Venkatesh, K. V. (2004). Effect of preculturing conditions on growth of Lactobacillus rhamnosus on medium containing glucose and citrate. Microbiological Research, 159(1), 35-42.

Krasaekoopt, W., Bhandari, B., \& Deeth, H. (2003). Evaluation of encapsulation techniques of probiotics for yoghurt. International Dairy Journal, 13(1), 3-13.

Leal-Calderon, F., Homer, S., Goh, A., \& Lundin, L. (2012). W/O/W emulsions with high internal droplet volume fraction. Food Hydrocolloids, 27(1), 30-41.

Maldonado-Valderrama, J., Wilde, P., Macierzanka, A., \& Mackie, A. (2011). The role of bile salts in digestion. Advances in Colloid and Interface Science, 165(1), 36-46.

Maldonado-Valderrama, J., Woodward, N. C., Gunning, A. P., Ridout, M. J., Husband, F. A., Mackie, A. R., ... Wilde, P. J. (2008). Interfacial characterization of beta-lactoglobulin networks: Displacement by bile salts. Langmuir, 24(13), 6759-6767.

Marchesi, J. R., Adams, D. H., Fava, F., Hermes, G. D., Hirschfield, G. M., Hold, G., .. Hart, A. (2016). The gut microbiota and host health: A new clinical frontier. Gut, 65(2), 330-339.

Minekus, M., Alminger, M., Alvito, P., Ballance, S., Bohn, T., Bourlieu, C., ... Brodkorb, A. (2014). A standardised static in vitro digestion method suitable for food - An international consensus. Food \& Function, 5(6), 1113-1124.

Nik, M. M., Wright, A. J., \& Corredig, M. (2010). Interfacial design of protein-stabilized emulsions for optimal delivery of nutrients. Food \& Function, 1(2), 141-148.

van Nood, E., Vrieze, A., Nieuwdorp, M., Fuentes, S., Zoetendal, E. G., de Vos, W. M., .. Keller, J. J. (2013). Duodenal infusion of donor feces for recurrent Clostridium difficile. The New England Journal of Medicine, 368(5), 407-415.

Ouwerkerk, J. P., van der Ark, K. C., Davids, M., Claassens, N. J., Robert Finestra, T., de Vos, W. M., \& Belzer, C. (2016). Adaptation of Akkermansia muciniphila to the oxicanoxic interface of the mucus layer. Applied and Environmental Microbiology, 82(23), 6983-6993.

Parker, T. G., \& Dalgleish, D. G. (1981). Binding of calcium-ions to bovine beta-casein. Journal of Dairy Research, 48(1), 71-76.

Pimentel-Gonzalez, D. J., Campos-Montiel, R. G., Lobato-Calleros, C., Pedroza-Islas, R., \& Vernon-Carter, E. J. (2009). Encapsulation of Lactobacillus rhamnosus in double emulsions formulated with sweet whey as emulsifier and survival in simulated gastrointestinal conditions. Food Research International, 42(2), 292-297.

Plovier, H., Everard, A., Druart, C., Depommier, C., Van Hul, M., Geurts, L., ... Cani, P. D. (2016). A purified membrane protein from Akkermansia muciniphila or the pasteurized bacterium improves metabolism in obese and diabetic mice. Nature Medicine.

Quevrain, E., Maubert, M. A., Michon, C., Chain, F., Marquant, R., Tailhades, J., ... Seksik, P. (2016). Identification of an anti-inflammatory protein from Faecalibacterium prausnitzii, a commensal bacterium deficient in Crohn's disease. Gut, 65(3), 415-425.

Sahin, S., Sawalha, H., \& Schroën, K. (2014). High throughput production of double emulsions using packed bed premix emulsification. Food Research International, 66, $78-85$.

Shima, M., Morita, Y., Yamashita, M., \& Adachi, S. (2006). Protection of Lactobacillus acidophilus from the low $\mathrm{pH}$ of a model gastric juice by incorporation in a W/O/W 
emulsion. Food Hydrocolloids, 20(8), 1164-1169.

Solanki, H. K., Pawar, D. D., Shah, D. A., Prajapati, V. D., Jani, G. K., Mulla, A. M., \& Thakar, P. M. (2013). Development of microencapsulation delivery system for longterm preservation of probiotics as biotherapeutics agent. BioMed Research International.

Su, J. H., Flanagan, J., \& Singh, H. (2008). Improving encapsulation efficiency and stability of water-in-oil-in-water emulsions using a modified gum arabic (Acacia (sen) SUPER GUM (TM)). Food Hydrocolloids, 22(1), 112-120.

Talwalkar, A., \& Kailasapathy, K. (2004). The role of oxygen in the viability of probiotic bacteria with reference to L. acidophilus and Bifidobacterium spp. Current Issues in Intestinal Microbiology, 5(1), 1-8.

Udayappan, S., Manneras-Holm, L., Chaplin-Scott, A., Belzer, C., Herrema, H., DallingaThie, G. M., ... Nieuwdorp, M. (2016). Oral treatment with Eubacterium hallii improves insulin sensitivity in $d b / d b$ mice. 2, 16009.

Vinarov, Z., Tcholakova, S., Damyanova, B., Atanasov, Y., Denkov, N. D., Stoyanov, S. D., ... Lips, A. (2012). Effects of emulsifier charge and concentration on pancreatic lipolysis: 2. Interplay of emulsifiers and biles. Langmuir, 28(33), 12140-12150.

Walter, A., \& Gutknecht, J. (1986). Permeability of small nonelectrolytes through lipid bilayer-membranes. Journal of Membrane Biology, 90(3), 207-217.

Wang, L., Christophersen, C. T., Sorich, M. J., Gerber, J. P., Angley, M. T., \& Conlon, M. A. (2011). Low relative abundances of the mucolytic bacterium Akkermansia muciniphila and Bifidobacterium spp. in feces of children with autism. Applied and Environmental Microbiology, 77(18), 6718-6721.

Yan, J., \& Pal, R. (2001). Osmotic swelling behavior of globules of W/O/W emulsion liquid membranes. Journal of Membrane Science, 190(1), 79-91. 